\title{
Dapoxetine: an evidence-based review of its effectiveness in treatment of premature ejaculation
}

This article was published in the following Dove Press journal:

Core Evidence

18 January 2012

Number of times this article has been viewed

\section{McCarty EJ \\ Dinsmore WW}

Department of Genitourinary Medicine, Royal Victoria Hospital, Belfast, Ireland
Correspondence: EJ McCarty Department of Genitourinary Medicine, Royal Victoria Hospital, GUM Level 3 OPD, Grosvenor Road, Belfast, BTI2 6BA, Ireland

Tel +3530289063 456I

Email ej_mccarty@hotmail.com
Abstract: Premature ejaculation (PE) is a major issue in male sexual health. The global prevalence of $\mathrm{PE}$ is estimated to be between $20 \%$ and $40 \%$, making it the most common sexual dysfunction in men. PE causes distress and reduced quality of life for patients and has a negative impact on interpersonal relationships. Historically, it has been treated with cognitive therapy, behavioral methods, and off-label use of selective serotonin reuptake inhibitors usually used to treat depression and other psychological disorders. Dapoxetine is a selective serotonin reuptake inhibitor specifically designed to treat PE. This paper reviews the current evidence for use of dapoxetine in the treatment of PE in adult men. There is substantial evidence that dapoxetine $30 \mathrm{mg}$ or $60 \mathrm{mg}$ taken "on-demand" results in a significant increase in intravaginal ejaculatory latency time when compared with placebo. Patient-reported outcomes are clearly improved relative to placebo following dapoxetine therapy, indicating greater control over ejaculation, more satisfaction with intercourse, less ejaculation-related distress, and, importantly, significantly reduced interpersonal difficulty. These data were supported by consistent reports of improvement in Clinical Global Impression of change in PE following treatment with dapoxetine. Further studies are needed to evaluate long-term efficacy and health economics. The unique pharmacology of dapoxetine makes it ideal for on-demand dosing, and the clinical evidence shows dapoxetine to be an efficacious and tolerable treatment for lifelong and acquired PE.

Keywords: dapoxetine, intravaginal ejaculatory latency time, patient-reported outcomes, premature ejaculation

\section{Scope, aims, and objectives}

Dapoxetine (Priligy ${ }^{\mathrm{TM}}$, Johnson and Johnson, Raritan, NJ) is the first and only product licensed for the treatment of premature ejaculation (PE) in men aged 18-64 years. At present, dapoxetine is licensed in ten countries, including several countries in Europe, and Mexico, South Korea, and New Zealand. ${ }^{1,2} \mathrm{PE}$ is the most common sexual dysfunction in men, with a global prevalence estimated to be between $20 \%$ and $40 \%$. $^{3-5}$ The uncertainty about prevalence figures is due to the intimate nature of the condition and, until recently, the lack of a universal evidence-based definition. It is probable that many men do not admit to having the condition and do not seek medical advice.

$\mathrm{PE}$ is characterized by ejaculation prior to, or soon after, vaginal penetration with minimal stimulation, with the male having no control over ejaculation. Definitions have been published by the International Society for Sexual Medicine and in the Diagnostic Statistical Manual of Mental Disorders, Fourth Edition, Text Revision (DSM-IV-TR), with the key point being the uncontrolled brevity of sexual intercourse. ${ }^{6-8}$ The negative consequences of PE are significant, and affect both the male and female partner. 
As well as obvious sexual dissatisfaction, the condition can cause personal distress, low self-esteem, and interpersonal difficulty. ${ }^{5,9-11}$

Dapoxetine belongs to a class of drugs called selective serotonin reuptake inhibitors (SSRIs) which are frequently used to treat depression. Prior to the availability of dapoxetine, psychotherapy (eg, cognitive behavior therapy) was widely used to treat PE. More recently, several SSRIs (other than dapoxetine) have been used off-label to treat PE. ${ }^{12,13}$ These SSRIs were not developed to treat PE, ${ }^{12}$ in contrast with dapoxetine which was specifically developed for this purpose and has a different pharmacological profile to the other SSRIs, ${ }^{14-17}$ with properties making it suitable for on-demand dosing. ${ }^{1}$

The aims of this article are to review the current evidence for use of dapoxetine in the treatment of PE, including the ability of the drug to not only increase time to ejaculation post-penetration, termed intravaginal ejaculatory latency time (IELT), but also to improve patient self-esteem, satisfaction with sexual intercourse, and perceived control over ejaculation.

\section{Methods}

Literature searches were carried out in August 2011 using PubMed (http://www.ncbi.nlm.nih.gov/pubmed), the Cochrane Database of Systematic Reviews (http://www. thecochranelibrary.com/view/0/AboutTheCochraneLibrary. html\#CDSR), NHS Evidence (http:/www.evidence.nhs.uk/ search?q=dapoxetine\&pa=2), and the National Institute for Health and Clinical Excellence (NICE, http://www.nice. org.uk). These databases were searched using the terms "dapoxetine" or "dapoxetine AND premature ejaculation".

Articles involving dapoxetine for the treatment of PE were identified, with priority given to systematic reviews, metaanalyses and integrated analyses, double-blind, randomized, placebo-controlled clinical trials (RCTs), and nonrandomized observational studies. Only articles published in English were selected for inclusion. The references listed in identified articles were used as a further source of relevant studies.

\section{Overview of premature ejaculation}

PE is highly prevalent and, due to the nature of the disorder, is likely to be under-reported and undertreated..$^{5,18}$ Reported prevalence has also been variable due to the previous lack of an evidence-based definition. In the past, physicians generally considered PE to have a psychological element, hence the historical use of psychotherapy to treat the condition. However, in recent years, the biological component has become more widely understood, and pharmacotherapy is the new focus for the treatment of PE.

Two types of PE have been widely recognized, ie, lifelong (primary) and acquired (secondary) PE. Lifelong PE is present from the first sexual experience onwards, occurs in almost all attempts at intercourse, and is considered to have a neurobiological etiology. Secondary PE occurs later in life after a period of perceived normal ejaculatory control, and may have a psychological and neurobiological etiology. This type of PE may be triggered by stress or linked to adverse events associated with medications. ${ }^{19,20}$ Waldinger et al suggested that, in addition to these well known types of PE, there are two other subtypes, ie, natural variable PE and premature-like ejaculatory dysfunction. ${ }^{21}$ Natural variable PE refers to those men reporting occasional early ejaculation in the course of normal events, whilst with the latter, men experience or complain of PE while having normal or prolonged IELT. ${ }^{22,23}$

Despite the above classifications, features common to all $\mathrm{PE}$ are an inability to control ejaculation, ejaculation prior to/soon after vaginal penetration, embarrassment, low selfesteem, personal distress, and often interpersonal difficulty and relationship problems as a result of the lack of sexual satisfaction for both the man and his partner., ${ }^{6,7}$ The first evidence-based definition of lifelong PE has recently been published by the International Society for Sexual Medicine, and includes the criterion of "ejaculation which always or nearly always occurs prior to or within about 1 minute of vaginal penetration", ie, an IELT of 1 minute or less. Other specified criteria are "... the inability to delay ejaculation on all or nearly all vaginal penetrations, and negative personal consequences, such as distress, bother, frustration and/or the avoidance of sexual intimacy" ${ }^{8}$ Prior to this, researchers recruiting patients for clinical studies of $\mathrm{PE}$ tended to use the definition given in the DSM-IV-TR, which is similar to that of the International Society for Sexual Medicine, but does not specify an IELT threshold. ${ }^{6}$

The etiology of PE is multifactorial, and associations with psychological, environmental, endocrine, and neurobiological factors have been made. Control of ejaculation is under neuronal control from the supraspinal level and involves various neurotransmitters, the most widely studied of which is serotonin (5-hydroxytryptamine, 5-HT). The role of 5-HT in the pathophysiology of PE is complex, with at least three receptor subtypes $\left(5-\mathrm{HT}_{1 \mathrm{a}}, 5-\mathrm{HT}_{1 \mathrm{~b}}, 5-\mathrm{HT}_{2 \mathrm{c}}\right)$ being known to play a role. ${ }^{24}$ Recently, there has been interest in investigating a potential genetic basis for PE. ${ }^{25}$ It is postulated that a polymorphism of the serotonin transporter 
gene (5-HTT) may be associated with the response to treatment with SSRIs. ${ }^{26}$

\section{Current therapeutic options}

Due to a perceived psychosomatic aspect of PE, psychotherapy, such as sex therapy or cognitive therapy, has been widely used historically to treat PE. ${ }^{12}$ The aim of such treatment is to encourage self-confidence and improve communication and intimacy between PE patients and their partners, in the hope of improving performance and reducing the anxiety associated with intercourse. Behavioral methods are also used to reduce the urgency to ejaculate, including squeezing the glans of the penis or intermittent penetration, although the latter may actually lead to prolonged sexual frustration rather than greater penetrative time ${ }^{27}$ Despite some reported short-term efficacy, there is little evidence of any long-term benefit associated with these treatment methods. ${ }^{1,9,28,29}$

The use of topical anesthetic creams was first described by Schapiro in 1943, the rationale being that reduced penile sensitivity would result in prolongation of sexual intercourse without adversely affecting the sensation of ejaculation..$^{30,31}$ Prilocaine/lidocaine cream (EMLA ${ }^{\circledR}$ ) has commonly been used off-license in the first-line management of PE. A novel metered-dose aerosol spray of lidocaine/prilocaine $\left(\mathrm{TEMPE}^{\circledR}\right.$ ) was found to increase IELT significantly compared with placebo (up to an eight-fold increase in one study) but is awaiting licensing. ${ }^{30,32-34}$ On face value, these topical treatments may appear ideal for on-demand use in PE, but they have several disadvantages, including genital numbness for both the patient and partner, reduced ability to maintain an erection, and messy application. ${ }^{12}$ As a result, these topical therapies have never achieved widespread acceptability.

The phosphodiesterase type 5 inhibitors, which are licensed for the treatment of erectile dysfunction, have been evaluated for use in PE. Despite their success in treating erectile dysfunction, there are limited data to support their use in PE alone. The only randomized, placebo-controlled, double-blind multicenter study evaluating sildenafil showed a 2.6-fold increase in IELT, but this was not statistically significant from placebo. ${ }^{35}$ However, it did show an improvement in ejaculatory control, confidence, and satisfaction in patient-derived questionnaires. A systematic review of 14 clinical trials assessing the efficacy of phosphodiesterase type 5 inhibitors and on-demand SSRIs concluded that wide ranges of IELT changes were due to inconsistencies in study designs and therefore are difficult to interpret reliably. ${ }^{36}$

Several years ago, the observation that one of the adverse effects of SSRIs when used to treat depression and other psychological disorders, ie, anorgasmia or delayed ejaculation, suggested SSRIs as a possible pharmacotherapy for PE. ${ }^{8,9}$ Subsequent research on the central and presynaptic involvement of 5-HT in ejaculation confirmed the mechanism of action of SSRIs in PE and marked a new era in pharmacotherapy for the condition. ${ }^{24}$

A number of SSRIs are currently used off-label in long-term daily dosing regimens for treatment of PE, including paroxetine, fluoxetine, fluvoxamine, sertraline, and citalopram. ${ }^{2}$ Paroxetine appears to be particularly effective at improving IELT; in one study, paroxetine $20-40 \mathrm{mg}$ per day over a 6-week period was found to increase median IELT by 9.5 minutes, while placebo provided no change in IELT $(P=0.002) .{ }^{37,38}$ Significantly increased IELT comes at a cost, because several adverse effects are commonly experienced with these SSRIs, including erectile dysfunction, loss of libido, mood changes, and discontinuation syndrome. ${ }^{12}$ Discontinuation syndrome consists of a cluster of psychological and somatic symptoms, including dizziness, headache, agitation, and insomnia, which may occur 1-3 days after stopping an SSRI and last for longer than 1 week, but subside on reintroduction of an SSRI.

A recent report by Koyunchu et al suggested that the use of escitalopram in the treatment of lifelong PE resulted in reduced semen parameters (specifically concentration, motility, and morphology) and could therefore have a negative effect on male fertility ${ }^{39}$ Further studies need to be done to establish a possible mechanism and determine if this observation is similar with other SSRIs.

Unlike the SSRIs mentioned above, dapoxetine was developed specifically for treatment of PE and is the only SSRI approved for treatment of the condition. What sets dapoxetine apart from other SSRIs currently used off-label to treat PE is its pharmacokinetic profile. ${ }^{15,16}$ Briefly, the pharmacology of dapoxetine may be summarized as follows:

- Dapoxetine is rapidly absorbed following oral administration, whereas other SSRIs take several days or even weeks to reach steady-state concentrations ${ }^{14}$

- Peak plasma levels of dapoxetine are reached in approximately 1 hour following a dose of $30 \mathrm{mg}$ or $60 \mathrm{mg}^{15,16}$

- Dapoxetine is rapidly eliminated; its initial half-life is approximately 1.4 hours for both doses, compared with 21 hours to 4 days for other SSRIs ${ }^{14}$

- Dapoxetine has a terminal half-life of 18.7 hours for the $30 \mathrm{mg}$ dose and 21.9 hours for the $60 \mathrm{mg}$ dose $\mathrm{e}^{15}$

- Even with multiple dosing, the pharmacokinetics of dapoxetine are unchanged, and it does not appear to accumulate significantly. ${ }^{15}$ 
These pharmacokinetic characteristics make dapoxetine ideal for on-demand dosing, which reduces the probability of unwanted side effects. ${ }^{15,40}$ Previous Phase II studies identified the optimal dose to be $30 \mathrm{mg}$ initially, with an increase to $60 \mathrm{mg}$ (the maximum recommended dose) if required. Pharmacodynamic studies identified the optimal dose administration time to be 1-3 hours before sexual intercourse. ${ }^{41}$

\section{Clinical evidence for dapoxetine}

From the literature searches, nine publications were identified for inclusion in the following evaluation of the clinical evidence for dapoxetine in the treatment of PE. These comprised three integrated analyses, six randomized placebocontrolled studies (two studies of identical design are only available as an integrated analysis), one subanalysis of two studies, and one long-term extension study.

In the following discussion, to aid critical analysis of the studies included for assessment, each publication has been assigned a "quality of evidence" rating based on the criteria shown in Table 1.

\section{Increase in IELT}

Due to the nature of PE, a change in IELT is the only diseaseorientated outcome that is regularly measured and reported. Other frequently reported outcomes are necessarily patientreported outcomes, and these are discussed later. Table 2 provides a summary of the identified studies reporting

Table I Levels of evidence applied to studies included in this review

\begin{tabular}{lll}
\hline $\begin{array}{l}\text { Strength of } \\
\text { evidence }\end{array}$ & Criteria & $\begin{array}{l}\text { Number } \\
\text { of studies }\end{array}$ \\
\hline Level I & $\begin{array}{l}\text { Strong evidence from at least } \\
\text { one systematic review, meta-analysis, } \\
\text { or integrated analysis } \\
\text { Evidence from randomized } \\
\text { controlled trials }\end{array}$ & 3 \\
Level 2 3 & $\begin{array}{l}\text { Evidence from nonrandomized well } \\
\text { designed trials, single-group pre/post } \\
\text { intervention, cohort, time series, }\end{array}$ & I \\
& $\begin{array}{l}\text { or matched-case control studies } \\
\text { Evidence from well designed, } \\
\text { nonexperimental, observational } \\
\text { studies from more than one center } \\
\text { or research group } \\
\text { Opinions of respected authorities, } \\
\text { based on clinical experience, } \\
\text { descriptive studies, and reports } \\
\text { of expert committees }\end{array}$ & 0 \\
\hline
\end{tabular}

Note: $*$ Two trials of identical design are only available as an integrated analysis ${ }^{16}$ and are included in the level I category.

Adapted from Clark and Mucklow. ${ }^{42}$ changes in IELT with dapoxetine and the quality of evidence supporting these changes. All of these studies were carried out before the recent definition of lifelong PE was published by the International Society for Sexual Medicine, ${ }^{8}$ so the recruitment criteria are based on the definition given by the DSM-IV-TR, ${ }^{6}$ with the added criterion of IELT $\leq 2$ minutes in at least $75 \%$ of sexual events (at least $90 \%$ of sexual events in Safarinejad ${ }^{43}$ ). In the studies listed in Table 2, IELT was measured using a stopwatch held by the partner during episodes of sexual intercourse and averaged over the specified baseline and treatment periods.

Stopwatch-measured IELT was reported in seven publications listed in Table 2, with the duration of these studies ranging from 9 to 24 weeks. Mean average IELT was significantly increased in all cases following treatment with dapoxetine $30 \mathrm{mg}$ or $60 \mathrm{mg}$, with end-of-study values being significantly greater than those for placebo, indicating an improvement in PE. The RCT by McMahon et al demonstrated significant increases from baseline in mean ( \pm standard deviation) IELT after just one dose of dapoxetine, ie, $30 \mathrm{mg}$ (1.1 [0.45]-2.7 [2.68] minutes), $60 \mathrm{mg}$ (1.1 [0.48]3.0 [3.19] minutes), and placebo (1.0 [0.47]-1.8 [1.71]; $P<0.001)$ for both doses of dapoxetine vs placebo. ${ }^{44}$ This significant difference from placebo was evident at all time points to the end of the study.

Of the seven studies in Table 2, four reported arithmetic and geometric means of average IELT, while three reported only one or the other. Geometric means give more conservative results that are less affected by data outliers, thus the values tend to be lower than those for arithmetic means. Where both geometric and arithmetic means were presented, the results for average IELT were similar for both methods. For example, in the integrated analysis of five Phase III studies, geometric mean IELT increased from 0.8 minutes at baseline in all groups to 2.0 and 2.3 minutes in those taking dapoxetine $30 \mathrm{mg}$ and $60 \mathrm{mg}$, respectively, compared with 1.3 minutes for those taking placebo (both $P<0.001$ ). ${ }^{45}$ The corresponding arithmetic means increased from 0.9 minutes at baseline to 3.1, 3.6, and 1.9 minutes, respectively (both $P<0.001$ vs placebo, Table 2).

Even in more extreme cases of $\mathrm{PE}$, in which baseline IELT was very short, treatment with dapoxetine effectively increased IELT. In the integrated analysis of two Phase III studies by Pryor et al, ${ }^{46}$ increases from baseline in average IELT at 12 weeks were significantly greater for either dose of dapoxetine (30 mg or $60 \mathrm{mg}$ ) than for placebo in the subgroups of patients with baseline average IELTs $\leq 1$ minute and $\leq 30$ seconds. The subanalysis of 
Table 2 Summary of evidence for end-of-study changes in intravaginal ejaculation latency time following treatment of premature ejaculation with dapoxetine

\begin{tabular}{|c|c|c|c|c|c|c|c|c|}
\hline \multirow[t]{2}{*}{$\begin{array}{l}\text { Level of } \\
\text { evidence }\end{array}$} & \multirow[t]{2}{*}{ Design } & \multirow[t]{2}{*}{$\begin{array}{l}\text { Treatment } \\
\text { and dose }\end{array}$} & & \multicolumn{3}{|c|}{$\begin{array}{l}\text { Intravaginal ejaculatory latency time } \\
\text { (minutes) }\end{array}$} & \multirow[t]{2}{*}{$\begin{array}{l}P \text { value } \\
\text { (vs placebo) }\end{array}$} & \multirow[t]{2}{*}{ Reference } \\
\hline & & & & Baseline & $\begin{array}{l}\text { Geometric } \\
\text { mean (SE) }\end{array}$ & $\begin{array}{l}\text { Arithmetic } \\
\text { mean (SD) }\end{array}$ & & \\
\hline \multirow[t]{6}{*}{ I } & Integrated analysis & DPX $30 \mathrm{mg}$ or & DPX 30 & $0.8(1.02)$ & $2.0(1.03)$ & & $<0.00 \mathrm{I}$ & McMahon \\
\hline & of five studies & $60 \mathrm{mg}$, or PBO & DPX 60 & $0.8(1.02)$ & $2.3(1.03)$ & & $<0.001$ & et $\mathrm{al}^{45}$ \\
\hline & & & PBO & $0.8(1.02)$ & I.3 (I.02) & & - & \\
\hline & & & DPX 30 & $0.9(0.49)$ & & $3.1(3.91)$ & $<0.001$ & \\
\hline & & & DPX 60 & $0.9(0.49)$ & & $3.6(3.85)$ & $<0.001$ & \\
\hline & & & PBO & $0.9(0.48)$ & & $1.9(2.43)$ & - & \\
\hline \multirow[t]{3}{*}{ I } & Integrated analysis & DPX $30 \mathrm{mg}$ or & DPX 30 & $0.92(0.50)$ & & $2.78(3.48)$ & $<0.000$ I & Pryor et al ${ }^{46}$ \\
\hline & of two studies & $60 \mathrm{mg}$, or PBO & DPX 60 & $0.91(0.48)$ & & $3.32(3.68)^{\dagger}$ & $<0.0001$ & \\
\hline & & & PBO & $0.90(0.47)$ & & $\mathrm{I} .75(2.2 \mathrm{I})$ & - & \\
\hline \multirow[t]{7}{*}{ I } & Integrated & DPX $30 \mathrm{mg}$ or & Acquired PE & & & & & Porst et al $\left.\right|^{47}$ \\
\hline & analysis of & $60 \mathrm{mg}$, or PBO & & & & & & \\
\hline & two studies $\#$ & & Geometric & $0.9(1.03)$ & & & $<0.001$ & \\
\hline & & & Arithmetic & $1.08(0.48)$ & $2.5 ; 2.9 ; 1.7$ & $4.0 ; 4.1 ; 2.5$ & $<0.001$ & \\
\hline & & & Lifelong PE & & & & & \\
\hline & & & Geometric & $0.8(1.02)$ & $2.2 ; 2.4 ; 1.2$ & $3.3 ; 3.6 ; 1.9$ & $<0.001$ & \\
\hline & & & Arithmetic & $0.92(0.48)$ & & & $<0.001$ & \\
\hline \multirow[t]{6}{*}{2} & Double-blind & DPX $30 \mathrm{mg}$ or & DPX 30 & $1.0(1.03)$ & $2.7(1.05)$ & & $<0.0001$ & McMahon \\
\hline & RCT, I 2 week & $60 \mathrm{mg}$, or PBO & DPX 60 & $0.9(1.04)$ & $3.1(1.05)$ & & $<0.0001$ & et $\mathrm{al}^{44}$ \\
\hline & $n=1067$ & & PBO & $0.90(1.04)$ & $1.8(1.05)$ & $3.9(3.94)$ & - & \\
\hline & & & DPX 30 & I.I (0.45) & & $4.2(3.97)$ & $<0.001$ & \\
\hline & & & DPX 60 & I.I (0.48) & & $2.4(2.05)$ & $<0.001$ & \\
\hline & & & PBO & $\mathrm{I} .0(0.47)$ & & & - & \\
\hline \multirow[t]{6}{*}{2} & Double-blind & DPX $30 \mathrm{mg}$ or & DPX 30 & $0.7(1.04)$ & $1.8(1.06)$ & & $<0.001$ & Buvat et al ${ }^{48}$ \\
\hline & RCT, 24 weeks, & $60 \mathrm{mg}$, or PBO & DPX 60 & $0.7(1.04)$ & $2.3(1.06)$ & & $<0.001$ & \\
\hline & $\mathrm{n}=1162$ & & PBO & $0.7(1.04)$ & I.I (I.06) & $3.1(4.88)$ & - & \\
\hline & & & DPX 30 & $0.9(0.50)$ & & $3.5(3.80)$ & $<0.001$ & \\
\hline & & & DPX 60 & $0.9(0.50)$ & & $1.9(2.89)$ & $<0.001$ & \\
\hline & & & PBO & $0.9(0.50)$ & & & - & \\
\hline \multirow[t]{2}{*}{2} & Double-blind & DPX $60 \mathrm{mg}$ & DPX 60 & 0.47 & 3.22 & & $0.00 \mathrm{I}^{\mathrm{a}}$ & Safarinejad ${ }^{43}$ \\
\hline & $\begin{array}{l}\text { RCT, } 12 \text { weeks, } \\
\mathrm{n}=2 \mathrm{I} 2\end{array}$ & $\begin{array}{l}\text { (30 mg twice- } \\
\text { daily), or PBO }\end{array}$ & PBO & 0.52 & 0.9 & & $0.08^{\mathrm{a}}$ & \\
\hline \multirow[t]{7}{*}{2} & Subanalysis of & DPX $30 \mathrm{mg}$ or & DPX & & & & & Shabsigh \\
\hline & integrated & $60 \mathrm{mg}$, or PBO & Patients with at & $0.9(0.47)$ & & $4.7(4.4 I)$ & Not reported & et $\mathrm{al}^{49}$ \\
\hline & analysis by & (Authors & least a 2-category & & & & & \\
\hline & Pryor et $\mathrm{a}^{46}$ & combined the & increase in control & & & & & \\
\hline & & data for DPX & Patients with less & $0.9(0.47)$ & & $1.7(1.90)$ & Not reported & \\
\hline & & 30 and $60 \mathrm{mg}$ ) & than a 2-category & & & & & \\
\hline & & & increase in control & & & & & \\
\hline
\end{tabular}

Notes: \#Only data for patients without erectile dysfunction are shown for consistency with other studies; ${ }^{\dagger} P<0.000 \mathrm{I}$ vs $30 \mathrm{mg}$ dapoxetine; ${ }^{a} P$ value is based on fold-increase from baseline, not difference from placebo as stated for the other studies.

Abbreviations: RCT, randomized controlled trial; SE, standard error; SD, standard deviation; PBO, placebo; DPX, dapoxetine; PE, premature ejaculation.

these studies by Shabsigh et a ${ }^{49}$ highlighted the importance of perceived control over ejaculation for achieving increases in IELT. Patients who reported at least a two-category improvement in control after 12 weeks of dapoxetine therapy recorded a mean change in IELT of $3.8(0.9-4.7)$ minutes, whereas those who reported less than a two-category improvement in control recorded a mean change in IELT of $0.8(0.9-1.7)$ minutes (Table 2). Overall, the consistent nature of the results from the studies identified indicates substantial evidence for a significant increase in IELT with dapoxetine $30 \mathrm{mg}$ and $60 \mathrm{mg}$, compared with placebo, in adult patients with $\mathrm{PE}$.

\section{Patient-reported outcomes}

In studies of PE, patient-reported outcomes form an important part of the evidence base because of the many ways in which PE can affect psychological wellbeing and quality of life, both for the patient and their sexual partner. The most 
frequently applied instrument in studies of PE is the Premature Ejaculation Profile, which is a validated tool designed to investigate various domains in $\mathrm{PE}$ and assess treatment efficacy. It comprises four self-reported items, each scored on a five-point scale, ie, perceived control over ejaculation, satisfaction with sexual intercourse, personal distress related to ejaculation, and interpersonal difficulty related to ejaculation. ${ }^{50}$

In addition, the Clinical Global Impression (CGI) of change is a validated instrument often used to give a measurement of overall perceived change in PE following treatment. The CGI (also called the patient-reported global impression of change in some studies) comprises just one item, ie, "Compared to the start of the study, how would you describe your premature ejaculation now?" Patients rate their response on a seven-point scale $(-3$ to +3$)$ as: much worse, worse, slightly worse, no change, slightly better, better, or much better. ${ }^{51}$

Studies reporting patient responses to items on the Premature Ejaculation Profile and the CGI of change are listed in Table 2, with quality of evidence indications. Each of the patient-reported outcomes is assessed individually below.

\section{Perceived improvement in control over ejaculation}

Changes from baseline in perceived control over ejaculation are reported for eight studies (Table 3). All three integrated analyses found significant improvements in control over ejaculation at study endpoint. In McMahon et al, in which the results from five RCTs were integrated, the proportion of patients who reported at least "good" control after 12 weeks of dapoxetine therapy increased from a baseline of $0.6 \%$ to $26.2 \%$ with dapoxetine $30 \mathrm{mg}$, and from $0.5 \%$ to $30.2 \%$ with dapoxetine $60 \mathrm{mg}$, compared with $0.3 \%$ to $11.2 \%$ with placebo $(P<0.001$ for both dapoxetine doses vs placebo). ${ }^{45}$

The integrated analysis by Porst et al of two studies showed no differences in control over ejaculation between those with lifelong or acquired PE (and no erectile dysfunction), suggesting that the etiology of the two forms may be similar, given that dapoxetine treatment was equally effective. ${ }^{47}$ The proportions of patients reporting at least "good" control at baseline and end-of-study were as follows:

- Acquired PE, $1 \%$ at baseline to $32 \%$ at end-of-study (dapoxetine $30 \mathrm{mg}$ ); $1 \%$ to $35 \%$ (dapoxetine $60 \mathrm{mg}$ ), and $1 \%$ to $19 \%$ (placebo)

- Lifelong PE, $0.5 \%$ at baseline to $29 \%$ at end-of-study (dapoxetine $30 \mathrm{mg}$ ); $0.5 \%$ to $28 \%$ (dapoxetine $60 \mathrm{mg}$ ), and $0.5 \%$ to $12 \%$ (placebo $)^{47}$
Significant improvement in ejaculatory control with dapoxetine $30 \mathrm{mg}$ or $60 \mathrm{mg}$, as compared with placebo, was found in all RCTs in Table 3. These improvements were noted not only at the end-of-study but at all time points in between. ${ }^{44,47,52}$

The long-term use of on-demand dapoxetine has been addressed in just one study (see Table 3), ie, a 9-month extension study of the two 12-week trials described by Pryor et al. ${ }^{47}$ All of the 1774 men enrolled in the extension study received on-demand dapoxetine $60 \mathrm{mg}$, regardless of prior treatment group in the original studies (dapoxetine $30 \mathrm{mg}, 60 \mathrm{mg}$, or placebo). At 9 months, approximately $70 \%$ of patients reported "fair", "good", or "very good" control over ejaculation. ${ }^{53}$ These data represent clear evidence of a significant improvement over placebo in perceived control over ejaculation in adult patients with PE taking dapoxetine $30 \mathrm{mg}$ or $60 \mathrm{mg}$ on-demand.

\section{Satisfaction with sexual intercourse}

Changes from baseline in satisfaction with sexual intercourse were reported in eight studies (Table 3). All three integrated analyses found significant improvements in satisfaction with sexual intercourse at study endpoint. In the analysis of two 12-week studies by Pryor et al, the proportion of patients receiving dapoxetine who reported at least "fair" satisfaction increased from approximately $50 \%$ at baseline to approximately $75 \%$ (dapoxetine $30 \mathrm{mg}$ ) and $80 \%$ (dapoxetine $60 \mathrm{mg}$ ) at end-of-study, compared with approximately 55\% with placebo $(P<0.001$ for both dapoxetine doses vs placebo; data estimated from Pryor et al). ${ }^{47}$ Furthermore, significant differences from baseline were seen at every time point for both doses of dapoxetine vs placebo (weeks 4, 8, and 12). Importantly, the partners of subjects in these trials also reported significant improvements in satisfaction with sexual intercourse at every time point, suggesting possible associated reductions in interpersonal difficulty (not measured in these studies). This integrated analysis also found a dose-dependent effect of dapoxetine, with significantly more patients on dapoxetine $60 \mathrm{mg}$ reporting at least "fair" satisfaction at every time point compared with those on dapoxetine $30 \mathrm{mg} .{ }^{47}$ Subanalysis of the trials published by Shabsigh et al highlighted the impact of greater perceived control over ejaculation on other aspects of sexual experience, with $74 \%$ of patients having at least a two-category increase in control-rated satisfaction with intercourse of "good" or "very good" at end-of-study. ${ }^{49}$

The integrated analysis of two studies by Porst et al showed no differences in satisfaction with intercourse 


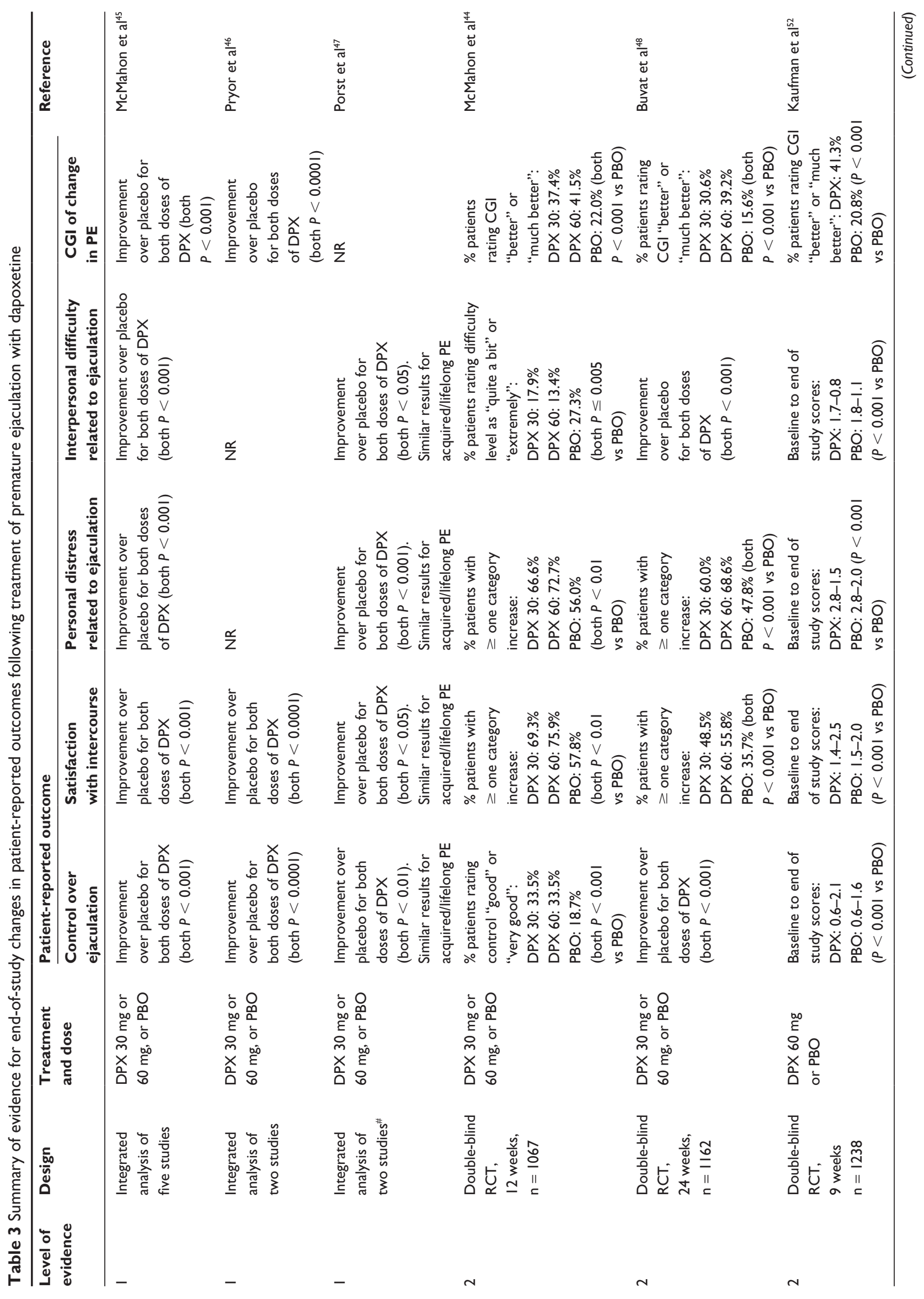




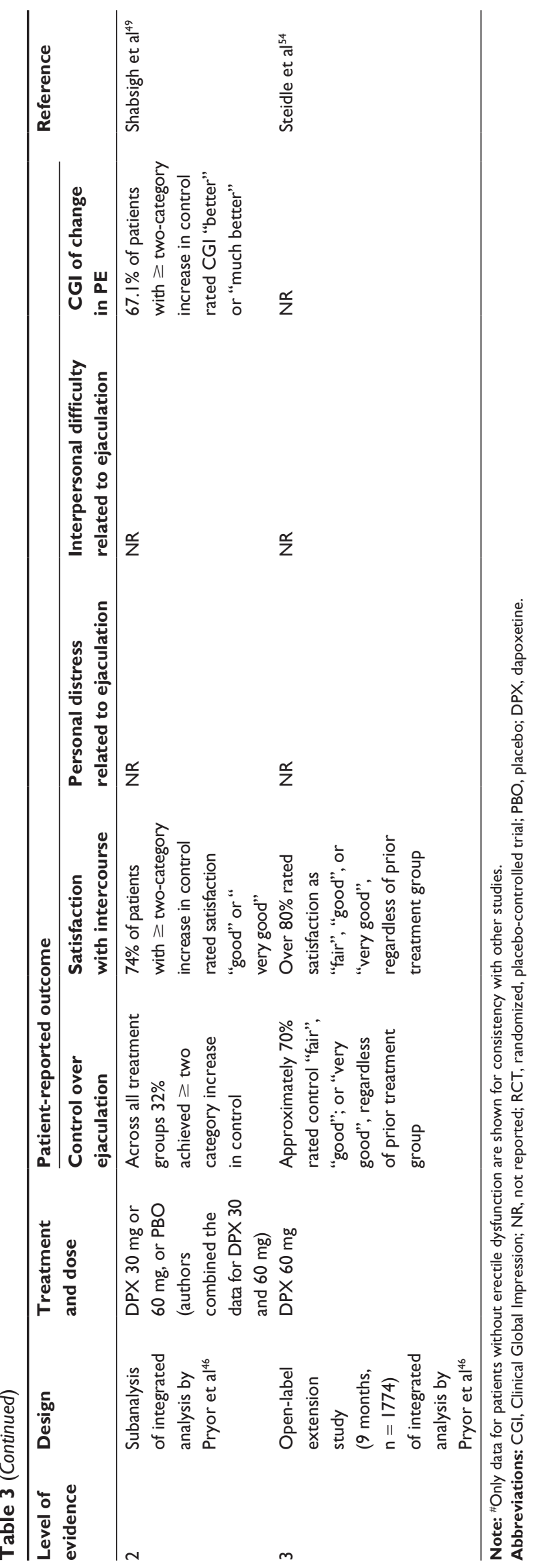

between those with lifelong or acquired PE (no erectile dysfunction), indicating that the two forms potentially share some pathophysiological elements. ${ }^{47}$ The proportions of patients reporting at least "good" satisfaction with intercourse at baseline and end-of-study (pooled 12-week data from a 12-week and a 24-week study) were as follows:

- Acquired PE, 7\% at baseline to 38\% at end-of-study (dapoxetine $30 \mathrm{mg}$ ); $7 \%$ to $42 \%$ (dapoxetine $60 \mathrm{mg}$ ) and $7 \%$ to $29 \%$ (placebo)

- Life-long PE, $10 \%$ at baseline to $40 \%$ at end-of-study (dapoxetine $30 \mathrm{mg}$ ); $10 \%$ to $38 \%$ (dapoxetine $60 \mathrm{mg}$ ) and $10 \%$ to $23 \%$ (placebo)

All three of the RCTs in Table 3 found significant improvements from baseline in satisfaction with intercourse compared with placebo at end-of-study and at all time points in between. For example, at end of the McMahon et al study, the proportions of patients who reported "good" or "very good" satisfaction with intercourse were $41.3 \%$ for dapoxetine $30 \mathrm{mg}, 40.9 \%$ for dapoxetine $60 \mathrm{mg}$, and $29.0 \%$ for placebo $(P<0.001$ for both doses of dapoxetine vs placebo). ${ }^{44}$

The effect of long-term dapoxetine treatment on satisfaction with sexual intercourse was examined in the nonrandomized extension study by Steidle et al (see Table 3). ${ }^{54}$ Irrespective of prior treatment (dapoxetine $30 \mathrm{mg}, 60 \mathrm{mg}$, or placebo), long-term on-demand use of dapoxetine $60 \mathrm{mg}$ resulted in more than $80 \%$ of patients reporting at least "fair" satisfaction with intercourse after 9 months. ${ }^{54}$ There is clear evidence from these studies that dapoxetine therapy in adult males with PE improves satisfaction with sexual intercourse in comparison with placebo.

\section{Personal distress related to ejaculation}

Five studies in Table 2 report changes from baseline in personal distress related to ejaculation, ie, two integrated analyses and three RCTs. Both integrated analyses found significant reductions in distress related to ejaculation at study endpoint following dapoxetine treatment. In the integrated analysis by McMahon et al, the proportions of patients who reported "quite a bit" or "extreme" personal distress decreased from $71.3 \%$ at baseline to $28.2 \%$ for dapoxetine $30 \mathrm{mg}$, and from $69.7 \%$ to $22.2 \%$ for dapoxetine $60 \mathrm{mg}$, compared with $73.5 \%$ to $41.9 \%$ with placebo $(P<0.001$ for both dapoxetine doses vs placebo $) .{ }^{45}$ As with the measures of ejaculatory control and sexual satisfaction, the integrated analysis of two studies by Porst et al found no differences in distress related to ejaculation between those with lifelong or acquired PE (and no erectile 
dysfunction). ${ }^{47}$ The proportion of patients reporting "quite a bit" or "extreme" personal distress at baseline and endof-study were as follows:

- Acquired PE, $73 \%$ at baseline to $23 \%$ at end-of-study (dapoxetine $30 \mathrm{mg}$ ), $73 \%$ to $20 \%$ (dapoxetine $60 \mathrm{mg}$ ), and $73 \%$ to $41 \%$ (placebo)

- Life-long PE, $71 \%$ at baseline to $28 \%$ at end-of study (dapoxetine $30 \mathrm{mg}$ ), $71 \%$ to $22 \%$ (dapoxetine $60 \mathrm{mg}$ ), and $71 \%$ to $44 \%$ (placebo).

All three of the RCTs in Table 2 reporting changes in personal distress related to ejaculation found significant improvements with dapoxetine therapy from baseline compared with placebo at end-of-study. Furthermore, one of these studies also found significant differences between dapoxetine (both $30 \mathrm{mg}$ and $60 \mathrm{mg}$ ) and placebo at all time points between baseline and end-of-study. ${ }^{44}$ In the RCT by Kaufman et al, the proportion of patients who reported being "not at all" or "a little bit" distressed by their ejaculation timing increased from approximately $5 \%$ at baseline to $54.3 \%$ at end-of-study for those who received dapoxetine $60 \mathrm{mg}$, compared with $35.3 \%$ for those who received placebo. ${ }^{52}$ Thus, there is clear evidence that personal distress related to the timing of ejaculation is significantly reduced with dapoxetine treatment, compared with placebo, in adults with PE.

\section{Interpersonal difficulty related to ejaculation}

Changes from baseline in interpersonal difficulty related to ejaculation following dapoxetine therapy were reported in five studies (Table 3). Two integrated analyses reporting this outcome found significant reductions in interpersonal difficulty related to ejaculation compared with placebo at study endpoint, ie, McMahon et al (integrated results from five studies) and Porst et al (integrated results from two studies). ${ }^{44,47}$ In the McMahon analysis, the proportions of patients who reported "quite a bit" or "extreme" interpersonal difficulty decreased from $36.1 \%$ at baseline to $12.3 \%$ for dapoxetine $60 \mathrm{mg}$ (there is an error in the publication for the dapoxetine $30 \mathrm{mg}$ results), compared with $38.5 \%$ to $23.8 \%$ with placebo $(P<0.001$ for dapoxetine $60 \mathrm{mg}$ vs placebo). ${ }^{44}$

The integrated analysis by Porst et al showed no differences in interpersonal difficulty related to ejaculation between those with lifelong or acquired PE (and no erectile dysfunction), adding further weight to the argument that lifelong and acquired PE have some shared etiology. ${ }^{47}$ The proportions of patients reporting "quite a bit" or "extreme" interpersonal difficulty at baseline and end-of-study were as follows:

- Acquired PE, $40 \%$ at baseline to $11 \%$ at the 12 -week end-of-study (dapoxetine $30 \mathrm{mg}$ and $60 \mathrm{mg}$ ) and $40 \%$ to $24 \%$ (placebo)

- Lifelong PE, $34 \%$ at baseline to $14 \%$ at end-of-study (dapoxetine $30 \mathrm{mg}$ ), $34 \%$ to $11 \%$ (dapoxetine $60 \mathrm{mg}$ ), and $34 \%$ to $26 \%$ (placebo)

All three of the RCTs in Table 2 reporting this outcome found significant improvements from baseline in interpersonal difficulty related to ejaculation compared with placebo at the study endpoint following dapoxetine treatment. In the RCT by Kaufman et al, the proportion of patients taking on-demand dapoxetine $60 \mathrm{mg}$ who reported "not at all" or "a little bit" of interpersonal difficulty related to ejaculation increased from $40.9 \%$ at baseline to $76.8 \%$ at the 9 -week study endpoint, compared with $43.0 \%$ to $64.2 \%$ for those taking placebo. ${ }^{52}$ Although comparative statistical analyses have not been employed in all of the above studies, the evidence suggests that dapoxetine (30 mg or $60 \mathrm{mg}$ ) is associated with an improvement in ejaculation-related interpersonal difficulty when compared with placebo.

\section{CGI of change in premature ejaculation}

The CGI of change in PE is a measure of a patient's overall perception of how their PE has changed following treatment. Patients' CGI responses following dapoxetine therapy are reported in six studies listed in Table 3 (note that three of these studies refer to this as patient global impression of change in PE or patient-reported global impression). The two integrated analyses reporting this outcome found significantly better CGI scores compared with placebo at study endpoint. In one of these, the proportions of patients who reported their condition to be "slightly better", "better", or "much better" at the end of the study (12 weeks) were 58\% (dapoxetine $30 \mathrm{mg}$ ) and $67 \%$ (dapoxetine $60 \mathrm{mg}$ ), compared with $26 \%$ with placebo $(P<0.0001$ for both dapoxetine doses vs placebo). ${ }^{47}$ Similarly, the study by McMahon et al found the proportions of patients who reported their PE to be at least "slightly better" at 12 weeks were 62.1\% (dapoxetine $30 \mathrm{mg}$ ) and $71.7 \%$ (dapoxetine $60 \mathrm{mg}$ ), compared with $36.0 \%$ with placebo $(P<0.0001$ for both dapoxetine doses vs placebo). ${ }^{45}$

All three of the RCTs in Table 3 found significantly better CGI scores with dapoxetine therapy compared with placebo at the study endpoints. At the 12-week end-of-treatment phase in the McMahon study, the proportions of patients who reported their PE to be at least "slightly better" were 
$71.4 \%$ (dapoxetine $30 \mathrm{mg}$ ), 79.2\% (dapoxetine $60 \mathrm{mg}$ ), and $52.8 \%$ (placebo, $P<0.001$ for both doses of dapoxetine vs placebo). ${ }^{44}$ The corresponding proportions for patients in this study who reported their PE to be at least "better" were $37.4 \%$ (dapoxetine $30 \mathrm{mg}$ ), $41.5 \%$ (dapoxetine $60 \mathrm{mg}$ ), and $22.0 \%$ (placebo, $P<0.001$ for both doses of dapoxetine vs placebo). ${ }^{44}$

The subanalysis by Shabsigh et al (of the integrated analysis reported by Pryor et $\mathrm{al}^{47}$ ) showed how perceived control over ejaculation is important for achieving an improved overall impression of PE. ${ }^{49}$ For example, 38.7\% of patients who reported at least a one-category increase in control also reported a CGI rating of "better" or "much better". Moreover, $67.1 \%$ of patients who reported at least a two-category increase in control also reported a CGI rating of "better" or "much better". Overall, dapoxetine (30 mg or $60 \mathrm{mg}$ ) is clearly associated with greater perceived overall improvement in PE compared with placebo.

\section{Patient-reported outcome-defined level of clinical benefit}

Three of the RCTs in Table 3 also reported a predefined composite clinical outcome as a measure of clinical benefit following dapoxetine treatment. ${ }^{44,48,52}$ It has been previously established that this composite is associated with improvements in IELT, satisfaction with intercourse, and the patients' global perception of PE. ${ }^{49}$ The composite patient-reported outcome was defined as a "two-category or greater increase in perceived control over ejaculation, and a one-category or greater decrease in ejaculation-related personal distress".

All three studies found a significantly greater proportion of patients achieving the composite patient-reported outcome with dapoxetine $30 \mathrm{mg}$ or $60 \mathrm{mg}$ than with placebo at the end of the treatment period. In the paper by McMahon et al, the proportions achieving the composite patient-reported outcome were $34.7 \%$ (dapoxetine $30 \mathrm{mg}$ ) and $37.2 \%$ (dapoxetine $60 \mathrm{mg}$ ), compared with $21.7 \%$ for placebo $(P<0.001$ for both doses of dapoxetine vs placebo). In the same study, patients achieving the composite patient-reported outcome reported longer IELTs than those reported by the overall treatment groups, ie, 5.4 minutes vs 3.9 minutes (dapoxetine $30 \mathrm{mg}$ ) and 4.2 minutes (dapoxetine $60 \mathrm{mg}$ ). ${ }^{44}$

The proportion of patients who achieved the composite patient-reported outcome was even larger in the Kaufman et al study in which $47.6 \%$ of patients who took dapoxetine $60 \mathrm{mg}$ on-demand achieved the composite patientreported outcome, compared with $21.7 \%$ of those taking placebo $(P<0.001$ for the difference between dapoxetine and placebo). ${ }^{52}$ This trial was only 9 weeks in duration, but positive results for this outcome measure were evident in the longer term. After 24 weeks of dapoxetine therapy, the trial by Buvat et al found $25.3 \%$ and $37.1 \%$ of patients achieved the composite patient-reported outcome with dapoxetine $30 \mathrm{mg}$ and $60 \mathrm{mg}$, respectively, compared with $13.0 \%$ with placebo $(P<0.001$ for both dapoxetine doses vs placebo). ${ }^{48}$

\section{Economic evidence}

Our literature search found no published health economics studies on the use of dapoxetine in adult patients with PE. The economic costs of dapoxetine should be assessed individually in all the countries where it is approved, since the relative costs to the health care provider differ according to local health care structure, currency, and costs of alternative therapy. Country-specific health economics studies are needed to answer the following questions:

- Is on-demand use of dapoxetine more cost-effective than long-term once-daily use of other SSRIs for treatment of PE?

- Is on-demand use of dapoxetine more cost-effective than psychotherapy?

\section{Dosage, administration, and formulation}

Oral dapoxetine is indicated for the treatment of men aged 18-64 years with premature ejaculation. The recommended starting dose is $30 \mathrm{mg}$ (administered with water) as needed, 1-3 hours prior to sexual intercourse (with a maximum dosing frequency of once every 24 hours). The dose may be increased to $60 \mathrm{mg}$ (the maximum recommended dose) based on efficacy and tolerability. Each film-coated tablet contains either $30 \mathrm{mg}$ or $60 \mathrm{mg}$ dapoxetine hydrochloride, and may be administered with or without food.

Dapoxetine is contraindicated in men with moderate to severe hepatic impairment and in those receiving concomitant therapy with potent cytochrome P450 3A4 inhibitors (eg, ketoconazole, ritonavir, telithromycin), thioridazine, monoamine oxidase inhibitors, serotonin reuptake inhibitors (eg, SSRIs, serotonin-norepinephrine reuptake inhibitors, tricyclic antidepressants) or other medicinal/herbal products with serotonergic effects (eg, hypericum [St John's wort]). Dapoxetine is not recommended in men with severe renal impairment, and caution is advised in men with mild to moderate renal impairment. Alcohol and recreational drugs should be avoided when taking dapoxetine. The above information is taken from the product monograph 
(http://www.sustinexprematureejaculation.com/pdf/Sustinex. pdf). Studies with concomitant use of dapoxetine and phosphodiesterase type 5 inhibitors do not show any significant interaction with tadalafil $20 \mathrm{mg}$ or sildenafil $100 \mathrm{mg}^{53}$

\section{Place in therapy}

The strongest evidence for the use of dapoxetine in adult males with premature ejaculation is for the main diseaseoriented outcome of IELT, reported in seven of the nine publications identified in our literature search (see Table 4). Dapoxetine significantly and consistently increased IELT by approximately 3-4 minutes, representing a 3-4-fold increase in IELT. Placebo, in contrast, generally resulted in just a two-fold increase in IELT. The disease-oriented efficacy of dapoxetine has been shown in the studies examined here to be supported by positive effects in all patient-reported outcomes, which together indicate a significant improvement in wellbeing and quality of life. Importantly, clear evidence was found for improvements in interpersonal relationships, suggesting that both sexual partners benefitted from dapoxetine treatment.

Despite a historical distinction between lifelong and acquired PE based on the time of life at which PE occurs, there is no evidence for a difference in response to dapoxetine in males with lifelong or acquired PE. Although increases in IELT were generally slightly smaller for those with lifelong PE than those with acquired PE (see Table 2), the differences were not deemed sufficiently large to discriminate between them. Moreover, differences between the two PE subtypes were less evident for patient-reported outcomes. This adds weight to the proposal for a single, unified definition of PE. However, this evidence is based on just one integrated analysis of two trials so further research is needed to verify these data. ${ }^{47}$

It is encouraging that the results obtained with dapoxetine therapy during trials of 9-24 weeks' duration have been shown to be maintained during long-term on-demand use.$^{54}$ However, it must be noted that evidence for this presently comes from one 9-month study of level 3 quality (it was nonrandomized and had no control group) in which patient-reported outcomes were measured, but not IELT. Therefore, more trials are required to add further evidence for the efficacy of long-term dapoxetine use in PE.

The great benefit of dapoxetine for the treatment of PE when compared with other SSRIs is that it can be taken as needed, which not only allows great flexibility and convenience but also limits exposure to adverse events. In all the studies examined above, dapoxetine tolerability has been consistently favorable; adverse events associated with dapoxetine are dose-dependent and tend to be nonsevere and nonserious. The most commonly reported treatment-emergent adverse events were nausea, dizziness, somnolence, diarrhea, headache, and vomiting. Table 5 shows the frequency of these treatment-emergent adverse events in the RCTs examined

Table 4 Summary of core evidence for dapoxetine in the treatment of lifelong or acquired premature ejaculation

\begin{tabular}{|c|c|c|}
\hline Outcome measure & Evidence & Implications \\
\hline \multicolumn{3}{|l|}{ Disease-oriented evidence } \\
\hline Increase in intravaginal ejaculatory latency time & Substantial & $\begin{array}{l}\text { Dapoxetine is consistently better than placebo at significantly } \\
\text { increasing intravaginal ejaculatory latency time }\end{array}$ \\
\hline \multicolumn{3}{|l|}{ Patient-oriented evidence } \\
\hline Perceived improvement in control over ejaculation & Clear & $\begin{array}{l}\text { Dapoxetine is better than placebo at giving men greater } \\
\text { perceived control over ejaculation }\end{array}$ \\
\hline Greater satisfaction with sexual intercourse & Clear & $\begin{array}{l}\text { Dapoxetine gives patients greater satisfaction with intercourse } \\
\text { compared with placebo }\end{array}$ \\
\hline Less personal distress related to ejaculation & Clear & $\begin{array}{l}\text { Distress ratings are significantly reduced with dapoxetine } \\
\text { compared with placebo }\end{array}$ \\
\hline Less interpersonal difficulty related to ejaculation & Clear & $\begin{array}{l}\text { Significantly reduced ratings for interpersonal difficulty with } \\
\text { dapoxetine compared with placebo }\end{array}$ \\
\hline $\begin{array}{l}\text { Improved clinical global impression of change in } \\
\text { premature ejaculation }\end{array}$ & Clear & $\begin{array}{l}\text { More patients who received dapoxetine reported a positive } \\
\text { change in premature ejaculation compared with those who } \\
\text { received placebo }\end{array}$ \\
\hline \multicolumn{3}{|l|}{ Economic evidence } \\
\hline $\begin{array}{l}\text { On-demand use of dapoxetine is more } \\
\text { cost-effective than long-term once-daily use of } \\
\text { other selective serotonin reuptake inhibitors for } \\
\text { treatment of premature ejaculation }\end{array}$ & No evidence & Health economics studies are needed \\
\hline $\begin{array}{l}\text { On-demand use of dapoxetine is more cost-effective } \\
\text { than psychotherapy }\end{array}$ & No evidence & Health economics studies are needed \\
\hline
\end{tabular}


Table 5 Summary of frequently reported treatment-emergent adverse events in trials of dapoxetine for the treatment of premature ejaculation

\begin{tabular}{|c|c|c|c|c|c|c|c|c|c|}
\hline \multirow[t]{2}{*}{ Reference } & \multirow[t]{2}{*}{ Design } & \multirow{2}{*}{$\begin{array}{l}\text { Treatment } \\
\text { and dose }\end{array}$} & & \multicolumn{6}{|c|}{ Treatment-emergent adverse events (\% patients) } \\
\hline & & & & Nausea & Diarrhea & Headache & Dizziness & Somnolence & Vomiting \\
\hline \multirow[t]{3}{*}{ Pryor et a $\mathrm{a}^{46, \Lambda}$} & Integrated & DPX $30 \mathrm{mg}$ or & DPX 30 & 8.7 & 3.9 & 5.9 & 3.0 & 3.2 & - \\
\hline & analysis of & $60 \mathrm{mg}$, or $\mathrm{PBO}$ & DPX 60 & 20.1 & 6.8 & 6.8 & 6.2 & 3.7 & \\
\hline & two studies & & PBO & 1.9 & 1.4 & 4.0 & 0.8 & 0.2 & \\
\hline \multirow[t]{3}{*}{ McMahon et al ${ }^{44, *}$} & Double-blind & DPX $30 \mathrm{mg}$ or & DPX 30 & 10.5 & 2.0 & 3.4 & 10.5 & 3.4 & 0.3 \\
\hline & RCT, 12 weeks, & $60 \mathrm{mg}$, or PBO & DPX 60 & 26.4 & 1.7 & 4.8 & 18.8 & 6.2 & 2.5 \\
\hline & $\mathrm{n}=1067$ & & PBO & 2.0 & 0.8 & 2.0 & 3.9 & 0.6 & 0 \\
\hline \multirow[t]{3}{*}{ Buvat et al ${ }^{48}$} & Double-blind & DPX $30 \mathrm{mg}$ or & DPX 30 & 16.5 & 3.9 & 6.4 & 7.7 & 3.9 & 1.3 \\
\hline & RCT, 24 weeks & $60 \mathrm{mg}$, or $\mathrm{PBO}$ & DPX 60 & 30.6 & 11.3 & 13.6 & 13.4 & 7.2 & 3.1 \\
\hline & $\mathrm{n}=1162$ & & PBO & 2.9 & 1.6 & 8.3 & 2.6 & 1.0 & 0.5 \\
\hline \multirow[t]{2}{*}{ Kaufman et a $\left.\right|^{52, \sim}$} & Double-blind & DPX $60 \mathrm{mg}$ or & DPX 60 & 15.3 & 6.1 & 8.1 & 10.2 & 3.7 & - \\
\hline & $\begin{array}{l}\mathrm{RCT}, 9 \text { weeks, } \\
\mathrm{n}=1238\end{array}$ & PBO & PBO & 1.6 & 2.0 & 6.1 & 2.9 & 0.8 & \\
\hline \multirow[t]{2}{*}{ Safarinejad ${ }^{43}$} & Double-blind & DPX $60 \mathrm{mg}$ & DPX 60 & 5.4 & 5.4 & 4.3 & 3.2 & - & - \\
\hline & $\begin{array}{l}\mathrm{RCT}, 12 \text { weeks, } \\
\mathrm{n}=2 \mathrm{I} 2\end{array}$ & $\begin{array}{l}\text { ( } 30 \mathrm{mg} \text { twice } \\
\text { daily), or PBO }\end{array}$ & PBO & 1.0 & 0 & 1.0 & 0 & & \\
\hline
\end{tabular}

Notes: ^ Treatment-emergent adverse events more frequent with dapoxetine than with placebo; *occurring in $\geq 1 \%$ of subjects; - occurring in $\geq 2 \%$ of subjects. Abbreviations: RCT, randomized, placebo-controlled trial; PBO, placebo; DPX, dapoxetine.

above for efficacy (please refer to the original publications for full lists of adverse events).

Less frequently reported treatment-emergent adverse events include erectile dysfunction, flushing, palpitations, upper respiratory tract infection, nasopharyngitis, loss of libido, insomnia, fatigue, dry mouth, anxiety, hyperhidrosis, abdominal pain, back pain, and asthenia. ${ }^{43,44,46,48}$

As may be expected, discontinuations due to treatmentemergent adverse events in the studies described here were reportedly more frequent with dapoxetine than with placebo, and more frequent with dapoxetine $60 \mathrm{mg}$ than with $30 \mathrm{mg}$. For example, in the trial by McMahon et al, $1.7 \%$ of patients on dapoxetine $30 \mathrm{mg}$ and $5.1 \%$ on dapoxetine $60 \mathrm{mg}$ discontinued the study, compared with $0.3 \%$ of patients on placebo. ${ }^{44}$ Nausea and dizziness were the most common treatmentemergent adverse events reported to cause discontinuation. ${ }^{44}$ Similarly, Buvat et al state nausea to be the most common treatment-emergent adverse event leading to discontinuation ( $1 \%$ of patients on dapoxetine $30 \mathrm{mg}, 2.6 \%$ on dapoxetine $60 \mathrm{mg}$, and $0.3 \%$ on placebo). ${ }^{48}$ In the trials by Pryor et al and Safarinejad, $5 \%$ and $6 \%$ of patients, respectively, discontinued due to treatment-emergent adverse events. ${ }^{43,46}$

Data on cardiovascular adverse events associated with dapoxetine in PE are somewhat inconsistent. In the study reported by Buvat et al, one patient experienced ventricular tachycardia and another patient had a transient ischemic attack (both receiving dapoxetine $30 \mathrm{mg}$ ), and a third patient experienced syncope followed by sinus bradycardia and sinus arrest (after receiving dapoxetine $60 \mathrm{mg}$ ). A fourth patient experienced syncope while on the higher dapoxetine dose. ${ }^{48}$ The trial by Kaufman et al reported syncope in two patients taking dapoxetine $60 \mathrm{mg}$ on-demand and in two patients taking the same dose once daily. ${ }^{52}$ In contrast, only one patient on dapoxetine ( $30 \mathrm{mg}$, plus two on placebo) experienced nonsustained ventricular tachycardia, and no patients reported any episodes of syncope in the McMahon et al trial, leading the authors to conclude that dapoxetine had no arrhythmogenic effects. ${ }^{44} \mathrm{~A}$ recent review of the cardiovascular safety profile of dapoxetine has examined data from the complete dapoxetine development program, including preclinical and Phase I studies, as well as the Phase III RCTs included in this review. It was concluded that dapoxetine is associated with vasovagal-mediated syncope (a temporary inability of the brain to control blood pressure and heart rate adequately causing syncope), but otherwise caused no other cardiovascular adverse events. ${ }^{55}$

\section{Conclusion}

Dapoxetine is the only drug specifically formulated and licensed for PE in adult males. The unique pharmacology of dapoxetine makes it ideal for on-demand dosing, allowing great convenience and flexibility for the patient. The clinical evidence published to date indicates that dapoxetine $30 \mathrm{mg}$ or $60 \mathrm{mg}$ is an efficacious and tolerable treatment for lifelong and acquired PE, leading to significant improvement not only in the main disease symptom of IELT, but also in all patient-reported outcomes. Dapoxetine is clearly a promising treatment option for $\mathrm{PE}$, and its use can result in greater quality 
of life for the patient and their sexual partner. With the recent greater emphasis on research in the field of PE, it is hoped that the evidence base for a range of treatments, both topical and oral, will grow and prove valuable for patients. ${ }^{56}$

\section{Disclosure}

The authors have received education, travel, and research grants from Bayer-Schering-Plough, Pfizer, Lilly, and Plethora.

\section{References}

1. Feige AM, Pinsky MR, Hellstrom WJ. Dapoxetine for premature ejaculation. Clin Pharmacol Ther. 2011;89(1):125-128.

2. McMahon CG. Dapoxetine for premature ejaculation. Expert Opin Pharmacother. 2010;11(10):1741-1752.

3. Althof SE. Prevalence, characteristics and implications of premature ejaculation/rapid ejaculation. J Urol. 2006;175(3 Pt 1):842-848.

4. Carson C, Gunn K. Premature ejaculation: definition and prevalence. Int J Impot Res. 2006;18 Suppl 1:S5-S13.

5. Porst H, Montorsi F, Rosen RC, Gaynor L, Grupe S, Alexander J. The Premature Ejaculation Prevalence and Attitudes (PEPA) survey: prevalence, comorbidities, and professional help-seeking. Eur Urol. 2007;51(3):816-823.

6. American Psychiatric Association. Diagnostic and Statistical Manual of Mental Disorders, Fourth Edition, Text Revision. Washington, DC American Psychiatric Association; 2000.

7. Colpi GM, Hargreave TB, Papp GK, Pomerol JM, Weidner W. Guidelines on Disorders of Ejaculation, 2001. Arnhem, The Netherlands: European Association of Urology; 2005.

8. McMahon CG, Althof SE, Waldinger MD, et al. An evidence-based definition of lifelong premature ejaculation: report of the International Society for Sexual Medicine (ISSM) ad hoc committee for the definition of premature ejaculation. J Sex Med. 2008;5(7):1590-1606.

9. Giuliano F, Hellstrom WJ. The pharmacological treatment of premature ejaculation. BJU Int. 2008;102(6):668-675.

10. Rowland D, Perelman M, Althof S, et al. Self-reported premature ejaculation and aspects of sexual functioning and satisfaction. $J$ Sex Med. 2004;1(2):225-232.

11. Sotomayor M. The burden of premature ejaculation: the patient's perspective. J Sex Med. 2005;2 Suppl 2:110-114.

12. Hellstrom WJ. Emerging treatments for premature ejaculation: focus on dapoxetine. Neuropsychiatr Dis Treat. 2009;5:37-46.

13. Waldinger MD, Zwinderman AH, Schweitzer DH, Olivier B. Relevance of methodological design for the interpretation of efficacy of drug treatment of premature ejaculation: a systematic review and metaanalysis. Int J Impot Res. 2004;16(4):369-381.

14. Hiemke C, Härtter S. Pharmacokinetics of selective serotonin reuptake inhibitors. Pharmacol Ther. 2000;85(1):11-28.

15. Modi NB, Dresser MJ, Simon M, Lin D, Desai D, Gupta S. Single- and multiple-dose pharmacokinetics of dapoxetine hydrochloride, a novel agent for the treatment of premature ejaculation. J Clin Pharmacol. 2006;46(3):301-309.

16. Thyssen A, Sharma O, Tianmei S, et al. Pharmacokinetics of dapoxetine hydrochloride in healthy Chinese, Japanese, and Caucasian men. J Clin Pharmacol. 2010;50(12):1450-1460.

17. Waldinger MD, Schweitzer DH, Olivier B. On-demand SSRI treatment of premature ejaculation: pharmacodynamic limitations for relevant ejaculation delay and consequent solutions. $J$ Sex Med. 2005; 2(1):121-131.

18. Moreira ED Jr, Brock G, Glasser DB, et al; GSSAB Investigators' Group. Help-seeking behaviour for sexual problems: the global study of sexual attitudes and behaviors. Int J Clin Pract. 2005;59(1): 6-16.
19. Kendirci M, Salem E, Hellstrom WJ. Dapoxetine, a novel selective serotonin transport inhibitor for the treatment of premature ejaculation. Ther Clin Risk Manag. 2007;3(2):277-289.

20. Waldinger MD. Recent advances in the classification, neurobiology and treatment of premature ejaculation. Adv Psychosom Med. 2008;29: $50-69$.

21. Waldinger MD, Schweizer DH. Changing paradigms from a historical DSM-III and DSM-IV view toward an evidence based definition of premature ejaculation. Part II - proposals for DSM-V and ICD-11. J Sex Med. 2006;3(4):693-705.

22. Waldinger MD, Schweizer DH. The use of old and recent DSM definitions of premature ejaculation in observational studies: a contribution to the present debate for a new classification of PE in the DSM-V. J Sex Med. 2008;5(5):1079-1087.

23. Waldinger MD. Premature ejaculation: different pathophysiologies and etiologies determine its treatment. J Sex Marital Ther. 2008;34(1): $1-13$.

24. Patel K, Hellstrom WJ. Central regulation of ejaculation and the therapeutic role of serotonergic agents in premature ejaculation. Curr Opin Investig Drugs. 2009;10(7):681-690.

25. Jern P, Santtila P, Johansson A, et al. Evidence for a genetic etiology to ejaculatory dysfunction. Int J Impot Res. 2009;21(1):62-67.

26. Safarinejad MR. Analysis of association between the 5-HTTLPR and STin2 polymorphisms in the serotonin-transporter gene and clinical response to a selective serotonin reuptake inhibitor (sertraline) in patients with premature ejaculation. BJU Int. 2010;105(1):73-78.

27. Abdel-Hamid IA, El Naggar EA, El Gilany AH. Assessment of as needed use of pharmacotherapy and the pause-squeeze technique in premature ejaculation. Int J Impot Res. 2001;13(1):41-45.

28. Hawton K, Catalan J, Martin P, Fagg J. Long-term outcome of sex therapy. Behav Res Ther. 1986;24(6):665-675.

29. McCabe MP. Evaluation of a cognitive behavior therapy program for people with sexual dysfunction. J Sex Marital Ther. 2001;27(3): 259-271.

30. Busato W, Galindo CC. Topical anaesthetic use for treating premature ejaculation: a double-blind, randomized, placebo-controlled study. $B J U$ Int. 2004;93(7):1018-1021.

31. Morales A, Barada J, Wyllie MG. A review of the current status of topical treatments for premature ejaculation. BJU Int. 2007;100(3):493-501.

32. Atikeler MK, Gecit I, Senol FA. Optimum usage of prilocaine-lidocaine cream in premature ejaculation. Andrologia. 2002;34(6):356-359.

33. Henry R, Morales A. Topical lidocaine-prilocaine spray for the treatment of premature ejaculation: a proof of concept study. Int J Impot Res. 2003;15(4):277-281.

34. Dinsmore WW, Hackett G, Goldmeier D, et al. Topical eutectic mixture for premature ejaculation (TEMPE): a novel aerosol-delivery form of lidocaine-prilocaine for treating premature ejaculation. BJU Int. 2007; 99(2):369-375.

35. McMahon CG, Stuckey BG, Anderson M, et al. Efficacy of sildenafil citrate (Viagra) in men with premature ejaculation. J Sex Med. 2005;2(3): 368-375.

36. McMahon CG, McMahon CN, Leow LJ, Winestock CG. Efficacy of type-5 phosphodiesterase inhibitors in the drug treatment of premature ejaculation: a systematic review. BJU Int. 2006;98(2):259-272.

37. Waldinger MD, Hengeveld MW, Zwinderman AH. Paroxetine treatment of premature ejaculation: a double-blind, randomized, placebocontrolled study. Am J Psychiatry. 1994;151(9):1377-1379.

38. Waldinger MD, Hengeveld MW, Zwinderman AH, Olivier B. Effect of SSRI antidepressants on ejaculation: a double-blind, randomized, placebo-controlled study with fluoxetine, fluvoxamine, paroxetine, and sertraline. J Clin Psychopharmacol. 1998;18(4):274-281.

39. Koyuncu H, Serefoglu EC, Yencilek E, Atalay H, Akbas NB, Sanca K. Escitalopram treatment for premature ejaculation has a negative effect on semen parameters. Int J Impot Res. 2011. [Epub ahead of print.]

40. Andersson KE, Mulhall JP, Wyllie MG. Pharmacokinetic and pharmacodynamics features of dapoxetine, a novel drug for 'on-demand' treatment of premature ejaculation. BJU Int. 2006;97(2):311-315. 
41. Lakemedelsverket Medical Products Agency. Public assessment report: scientific discussion: Priligy dapoxetine hydrochloride filmcoated tablets, 30 and $60 \mathrm{mg}$; December 2008. Available at: http://www. lakemedelsverket.se/SPC_PIL/Pdf/par/Priligy $\% 20$ film-coated $\% 20$ tablet.pdf. Accessed November 6, 2011.

42. Clark W, Mucklow J. Gathering and weighing the evidence. In: Panton R, Chapman S, editors. Medicines Management. London, UK: BMJ Books and Pharmaceutical Press; 1998.

43. Safarinejad MR. Safety and efficacy of dapoxetine in the treatment of premature ejaculation: a double-blind, placebo-controlled, fixeddose, randomized study. Neuropsychopharmacology. 2008;33(6): 1259-1265.

44. McMahon C, Kim SW, Park NC, et al; Dapoxetine 3003 Study Investigators. Treatment of premature ejaculation in the Asia-Pacific region: results from a phase III double-blind, parallel-group study of dapoxetine. J Sex Med. 2010;7(1 Pt 1):256-268.

45. McMahon CG, Althof SE, Kaufman JM, et al. Efficacy and safety of dapoxetine for the treatment of premature ejaculation: integrated analysis of results from five phase 3 trials. J Sex Med. 2011;8(2):524-539.

46. Pryor JL, Althof SE, Steidle C; Dapoxetine Study Group. Efficacy and tolerability of dapoxetine in treatment of premature ejaculation: an integrated analysis of two double-blind, randomised controlled trials. Lancet. 2006;368(9539):929-937.

47. Porst H, McMahon CG, Althof SE, et al. Baseline characteristics and treatment outcomes for men with acquired or lifelong premature ejaculation with mild or no erectile dysfunction: integrated analyses of two phase 3 dapoxetine trials. J Sex Med. 2010;7(6):2231-2242.

48. Buvat J, Tesfaye F, Rothman M, Rivas DA, Giuliano F. Dapoxetine for the treatment of premature ejaculation: results from a randomized, double-blind, placebo-controlled phase 3 trial in 22 countries. Eur Urol. 2009;55(4):957-967.
49. Shabsigh R, Patrick DL, Rowland DL, Bull SA, Tesfaye F, Rothman M. Perceived control over ejaculation is central to treatment benefit in men with premature ejaculation: results from phase III trials with dapoxetine. BJU Int. 2008;102(7):824-828.

50. Patrick DL, Giuliano F, Ho KF, Gagnon DD, McNulty P, Rothman M. The premature ejaculation profile: validation of self-reported outcome measures for research and practice. BJU Int. 2009;103(3):358-364.

51. Althof SE, Brock GB, Rosen RC, et al. Validity of the patient-reported Clinical Global Impression of Change as a measure of treatment response in men with premature ejaculation. J Sex Med. 2010;7(6):2243-2252.

52. Kaufman JM, Rosen RC, Mudumbi RV, Tesfaye F, Hashmonay R, Rivas D. Treatment benefit of dapoxetine for premature ejaculation: results from a placebo-controlled phase III trial. BJU Int. 2009;103(5): 651-658.

53. Dresser MJ, Desai D, Gidwani S. Dapoxetine, a novel treatment for premature ejaculation does not have pharmacokinetic interactions with phosphodiesterase-5 inhibitors. Int J Impot Res. 2006;18:104-110.

54. Steidle C, Miloslavsky M, Bull S; The Dapoxetine Study Group. Long-term efficacy of dapoxetine for the treatment of premature ejaculation (PE). Poster presented at the Fall meeting of the Sexual Medicine Society of North America, New York, NY; November 17-20, 2005.

55. Kowey PR, Mudumbi RV, Aquilina JW, DiBattiste PM. Cardiovascular safety profile of dapoxetine during the premarketing evaluation. Drugs R D. 2011;11(1):1-11.

56. McCarty EJ, Dinsmore WW. Premature ejaculation: treatment update. Int J STD AIDS. 2010;21(2):77-78.
Core Evidence

\section{Publish your work in this journal}

Core Evidence is an international, peer-reviewed open-access journal evaluating the evidence underlying the potential place in therapy of drugs throughout their development lifecycle from preclinical to postlaunch. The focus of each review is to evaluate the case for a new drug or class in outcome terms in specific indications and patient groups.

\section{Dovepress}

The manuscript management system is completely online and includes a very quick and fair peer-review system, which is all easy to use. Visit http://www.dovepress.com/testimonials.php to read real quotes from published authors. 